\title{
Research and Construction of Traditional Culture Education System for Children
}

\author{
Duoling Pan \\ Department of Humanities \\ Yuzhang Normal University \\ Nanchang, China 330103
}

\begin{abstract}
The unity of children's development and cultural continuity is the fundamental principle of traditional culture education for children. From the nature, traditional culture education for children is aesthetic education instead of behavior education and ideological education; its educational content should focus on Chinese traditional art; its purpose is to build a knowable and sensible image of China in children's minds. From education strategy, traditional culture education for children should integrate home education with school education, but center on home education and combine reading with audio-visual material, but center on reading; should combine artistic practice with life practice, but center on life practice.
\end{abstract}

Keywords-pre-school education; children; traditional culture education; aesthetic education

\section{INTRODUCTION}

Compared with traditional culture education in other stages, traditional culture education for children is a relatively weak link. At present, there is little research on how to carry out traditional culture education for children. Therefore, this paper attempts to construct the fundamental system of traditional culture education for children by discussing several key issues such as the principle, nature, content, goal and strategy of traditional culture education for children.

\section{PRINCIPLE OF TRADitional CUlTURE EdUCATION} FOR CHILDREN: THE UNITY OF CHILDREN'S DEVELOPMENT AND CULTURAL CONTINUITY

Traditional culture education for children means education for preschool children on the one hand, and traditional culture education on the other hand. There is no doubt that the two aspects can be integrated with each other, but if not properly handled, they will conflict with each other, resulting in the distortion and deterioration of traditional culture education for children, which is a fruitless effort ultimately. There are two main reasons why these two aspects may conflict with each other.

First, traditional culture education for children has the possibility of considering children as the tool of cultural inheritance and development. The word "traditional" has the meaning of "native" and "own". The "tradition" of traditional culture is relative to foreign culture. The special emphasis on the "traditional" attribute of culture is often a phenomenon that occurs when native culture faces the competition pressure from foreign culture. Whether it is "Hua-Yi Distinction" proposed by Han Yu, "Utilization of West in Chinese Form" advocated by westernizationists in the late Qing Dynasty, or Chinese Quintessence School's defense for Chinese classical culture in the period of New Culture Movement, they have the meaning of native culture contending with foreign culture to obtain living space for native culture. Traditional culture education is generated under the stimulation of the sense of cultural crisis, one of whose important mission is to inherit and continue excellent native culture and fight for living space for native culture, so as to maintain the cultural security of the country, and then to maintain the political and economic security of the country. Therefore, traditional culture education has a distinct social utilitarian color. However, the fundamental purpose of education is to promote human development. Human development is the purpose of not the means of cultural development. The social utilitarianism color of traditional culture education is not in harmony with the fundamental purpose of education, nor is it in harmony with the "childcentered" idea in pre-school education.

For example, some people think that some content in Disciple Gauge are consistent with that in Guideline to the Learning and Development of Children Aged 3 - 6, so reading Disciple Gauge is good for the development of children. Indeed, the author thinks that "Wash your face when you get up in the morning, and brush your teeth. After using a toilet, always wash your hands.", "When it comes to eating and drinking, do not pick and choose your food. Eat only the right amount; do not over-eat" etc. in Disciple Gauge have similar meaning to "Brush your teeth every morning and evening, and wash your hands before meals and after using a toilet" in Guideline to the Learning and Development of Children Aged 3 - 6. [2] Now that they are the same, why do we choose "Wash your face when you get up in the morning, and brush your teeth. After using a toilet, always you're your hands", such a sentence hard to pronounce and difficult for children to understand, instead of "Brush your teeth every morning and evening, and wash your hands before meals and after using a toilet", a sentence that is concise, clear and easy to understand in education activities? Does the sentence "Brush your teeth every 
morning and evening, and wash your hands before meals and after using a toilet" have to be said by the ancients to be scientific? It has no practical significance to make children understand "Brush your teeth every morning and evening, and wash your hands before meals and after using a toilet" via "Wash your face when you get up in the morning, and brush your teeth. After using a toilet, always wash your hands.", but takes children a lot of time and energy. This behavior shows that under the banner of traditional culture education, children become tools of cultural development.

Second, there is a possibility that traditional culture education for children may suppress the vitality and creativity of children. The social utilitarianism color of traditional culture education implies the tendency to use the society and collectivity to suppress individuals and individuality; when such a tendency combines with the principle of feudal moral conduct and the ideology of hierarchy, it will cause more worry of educators. Such a worry is not unnecessary. For example, "filial piety" is a traditional virtue of the Chinese nation and an important thought and criterion in traditional Chinese culture, but in traditional Chinese culture, when "filial piety" is associated with "loyalty", it often reflects the unconditional obedience of the "lower level" to "higher level". This kind of obedience even goes down to the soul and becomes an unconscious behavior, which leads to the nominal legitimacy of individual behavior covering up the essential injustice. This is why although "burying the son to attend upon the mother" in the "24 stories of filial piety" reflects undisguisedly contempt for human nature, it is still popular with some people. For another example, the word "should" in "When your parents need to instruct you, you should listen with patient respect." in Disciple Gauge reflects the absolute authority of parents in traditional society, but this is still considered reasonable and natural. In the period of New Culture Movement, Scholars such as Lu Xun criticized Chinese traditional culture fiercely. One of the important reasons is that they believe that Chinese traditional culture suppresses the vitality and creativity of individuals. Although Lu Xun, et.al. made the mistake of hypercorrection when criticizing traditional culture, their criticism of traditional culture is profound, even if it is only "one-sidedly profound". Lu Xun and others criticized traditional culture in order to achieve "emancipation of human". To achieve emancipation of human, the first step is to achieve "emancipation of children." Therefore, the promotion of traditional culture education for children in the early childhood may cause confusion of some people who worry that traditional culture education may kill children's nature.

Because the traditional culture education of children has the possibility to make children the tool of cultural inheritance and development and to suppress their vitality and creativity, the traditional culture education for children should firmly adhere to the principle of unifying the children's development and cultural continuity. This is the basic principle of traditional culture education for children. The traditional culture education has to be the traditional education and education for children as well, which means that all conceptions of traditional culture education for children should be established based on children's cognitive and psychological characteristics, and can play a sustaining and long-term role in promoting children's development. Only by adhering to this principle, we can effectively discuss the nature, content, goal, strategy, etc., of traditional culture education for children.

\section{NATURE, CONTENT AND GOAL OF TRADITIONAL CULTURE EDUCATION FOR CHILDREN}

Children have limited language competence, but they still have a strong ability of comprehension. Children's comprehension is achieved through empathy, that is, not through logical reasoning, but mainly through the intuitive situations. The characteristics of children's psychological cognition determine the nature, content and goal of traditional culture education for children.

\section{A. Nature of Traditional Culture Education for Children: Aesthetic Education}

Traditional culture education for children shall be aesthetic education resorting to children's soul instead of ideological education and behavior education resorting to their cognition and rationality. Children lack logical thinking ability relatively, but they have strong emotional experience ability. By combining with children's cognitive characteristics, traditional culture education for children is rather "infection" and "edification" than "education" and "learning", which aims to make children feel the beauty and poetry of traditional culture. Such a feeling in the hearts of children is equivalent to a seed which will take root, sprout and grow into a tree in the future as long as the environment is right. Therefore, traditional culture education for children should be aesthetic education resorting to children's soul

1) An important characteristic of aesthetic education is that it is free: The thought of aesthetic education is rooted in Schiller's theory of "instinct of play". What Schiller said "play" is not a game in real life, but a free and conscious activity opposite to compulsory activities. It is a kind of aesthetic and artistic game of non-utilitarian, in which ideal and all-round people are developed. [3] Compared with behavior education characterized by "discipline" and ideological education characterized by "preach", aesthetic education emphasizes the "infection" and "edification" of education on people's mind. Only in free games, can external knowledge be transformed into spiritual cultivation and truly change people's thoughts and behaviors. Only when the humanistic thought, moral concern and value ideas in traditional Chinese culture really enter the hearts of Chinese people can the traditional culture education be the fountainhead of fresh water and be able to constantly nurture people's minds

2) Another important feature of aesthetic education is that it emphasizes experience more than cognition: Through the experience instead of logical thinking, people directly feel the beauty contained in the brilliant culture of human beings, so as to be attracted by it, then accept and 
maintain it. In such a process, people can achieve the continuation of culture and spiritual sublimation of their own. Children have the corresponding experience ability, so they can intuitively feel the most charming part of language, picture and music. Therefore, compared with education and education, aesthetic education is more feasible for children. Of course, this does not mean that traditional culture education for children should not have an impact on children's thoughts and behaviors, but that this impact is the objective result of the traditional culture education for children, not an active pursuit.

\section{B. Content of Traditional Culture Education for Children: Traditional Art}

Since the nature of traditional culture education for children should be aesthetic education, then, Chinese traditional art should become the most appropriate content of traditional culture education for children. The traditional art here not only includes arts in a narrow sense such as traditional poetry, music, dance, painting and calligraphy, but also includes the art in our daily life based on traditional Chinese festivals and customs. First, Chinese traditional art is characterized by visualization, emotionality and life orientation, which conforms to the psychological and cognitive characteristics of children and has strong attraction for them. Secondly, the world of art has no limit and will expand with the growth of children's age and mind, so that children can still explore and benefit from this world in the future life stage, which makes traditional culture education for children more sustainable. Therefore, traditional art is not only a gate of but also a grand hall of traditional culture education for children.

\section{Goal of Traditional Culture Education for Children: to Build a Concrete and Sensible Image of China in Children's Minds}

Traditional culture education for children takes Chinese traditional art as the main content, which not requires children to master the rules and standards of Chinese traditional art. If it does, it will again become the knowledge education. The goal of traditional culture education for children is to build a concrete and sensible image of China in children's minds. Such a concrete and sensible image of China is built through children's experience of the poetry and beauty of Chinese traditional art instead of through their cognition, which is the result of subtle influence of art on children's minds, reflecting children's affective identification of Chinese traditional art from the heart. Only when this goal is achieved can we say the traditional culture education for children is effective.

\section{IMPLEMENTATION STRATEGY OF TRADITIONAL CULTURE EDUCATION FOR CHILDREN}

\section{A. Combining Home Education with School Education, But Centering on Home Education}

Many people mistakenly believe that education is only the responsibility of schools and ignore that family is the real foundation of education. Certainly, traditional culture education for children needs close cooperation of families and kindergartens, and kindergartens can integrate traditional culture education for children into daily teaching, teaching environment settings and play activities, but kindergartens have their own teaching tasks. Therefore, if we pass the task of traditional culture education for children to kindergartens, this will increase the burden on children in the end. At the same time, traditional culture education is aesthetic education, whose edification effect needs to be gradually realized with time. Therefore, traditional culture education for children shall be the responsibility of family and carried out leisurely in the daily life of the family.

\section{B. Combining Reading with Audio-visual Material, But Centering on Reading}

Audio-visual material can play an important role in traditional culture education for children. In recent years, TV screens have been flooded by cartoons lacking nutrition, such as Boonie Bears and Pleasant Goat and Big Big Wolf. This makes people forget that in the early years, cartoons China independently produced had reached a high level, and such cartoons not only made great achievements in language, plot, picture and music, but also had distinct traditional styles and interestingness. For example, the cartoon Thirty-six Characters, released in 1984, tells the origin and characteristics of Chinese characters by using vivid images and interesting plots, which is no inferior to excellent overseas cartoons, even today. In 1961, the cartoon Little Tadpoles Search for Their Mother was released, whose exquisite ink painting style is still amazing even today. There are also a number of excellent domestic cartoons like Feeling from Mountain and Water and Shepherds' Bamboo Flute, which all reflect the pure Chinese charm. These cartoons are good materials for traditional culture education for children.

Although audio-visual materials are more attractive for children, from the long-term development of children, reading, undoubtedly, has more important significance, because reading points to a broader world. Children do not have independent reading ability, so children's reading requires parent-child joint reading. The best books for children to read are picture books. Picture books combine stories and pictures together, which conforms to children's cognitive and aesthetic habits, so they are deeply loved by children. Some outstanding Chinese style picture books bear traditional Chinese culture from all aspects. For example, the picture book The Ballad of Mulan produced by Cai Gao expresses traditional Chinese poetry in the form of fresco; Magic Horse produced by Chen Jianghong mimics many famous traditional Chinese paintings in the form of traditional Chinese realistic painting, including Han Banquet Map by Gu Hongzhong, the Painting of Lady of Guoguo Spring Outing by Zhang Xuan, Bu Nian Tu by Yan Liben, Copied Grazing Horses Painting of Wei Yan by Li Gonglin and Painting of Horse Bathing by Zhao Mengfu. When expounding western picture books' mimicking of art classics, Sipe said that mimicking of art classics by picture books removes the mystery of high art and makes high art closer to children, which can help children get the pleasure of art 
appreciation, and get the preliminary experience of art, so as to provide children with an opportunity into the art classics [4]. For instance, picture books of Chen Jianghong, Chen Jianghong said: "All the valuable, meaningful and elegant traditions are disappearing. For me, the most important thing is to preserve these cultures that I value and share them with all people in the world". Chen Jianghong's picture books have realized his cultural dream, and through his picture books, the classical Chinese art has airily entered the heart of children.

In reading and audio-visual activities, children can get familiar with various elements and forms of traditional Chinese art, and feel the unique beauty and charm of traditional Chinese art. In this way, traditional Chinese culture is no longer an abstract concept in their minds, but concrete and tangible image. Such traditional culture education must have a profound and lasting influence on their minds.

\section{Combining Artistic Practice with Life Practice, But Centering on Life Practice}

The so-called artistic practice means the artistic learning and practice with due intentions while the living practice refers to the non-utilitarianism activities with artistic taste in life. Artistic practice is necessary to help the children to understand art, master the skills of art and form the aesthetic judgment. However, although the excessive infusion of artistic skills to preschool children or requirement on preschool children to conduct art practice in strict accordance with the models may temporarily enable the creation of children to conform to the adult $\mathrm{s}$ and obtain the recognition of adults, the consequence thereof is that the vivid art is changed into boring knowledge in the long term. It constrains the imagination and creativity of children and may also impede the mental development of children." When the children follow the existing contour lines to draw, they have already lost the capacity to handle the relationship between human and nature with the rich creativity"[5], therefore, Lowenfeld strongly opposes that adults intervene with the drawing learning of children to guarantee the visualized and unrestrained creativity of Children and guarantee them not to be harmed.

The traditional culture education for children shall mainly be dominated by living practice to integrate the artistic activities with traditional elements, charm and style into the lives of children and promote the daily life into artistic life which is the essential path for traditional culture education.

Essentially, the Chinese traditional culture is a kind of poetic culture which is full of art of living everywhere and the season, festival, diet, cloth, house living and poems are all like that. In term of the 24 solar terms used by ancients for dividing seasons, the name of season itself is poem. For example, "Qingming" is named from the sentence "when everything is clean, clear and bright, the weather becomes fresh and cool and things seem clear and bright and everything will become so bright at that time." At such moment, people can take children to have an outgoing in spring, sacrifice and renovate the tombs and fly kites; read the poems about Qingming, enjoy the picture books about Qingming and manifest the scene seen and things occurred in the day through lines and colors after going home. And the spirits and charm of traditional culture will enter the deep heart of children unknowingly through such mode. Only at such moment when the culture is directly connected with individual living and development and the individual vital movement can the culture education be the kind of education with continuous functions and impact the whole life of children. Through such mode, the Chinese traditional culture can be better inherited and extended from generation to generation.

\section{CONCLUSION}

Traditional culture is the soul of a country and a nation, the spiritual lifeblood of a society and the source of individual creativity. Carrying forward excellent traditional culture is of great significance for forging common belief of the nation, developing national spirit, sharpening personal personality cultivation and improving the personal ideological level. Therefore, traditional culture education for children is a complex but significant project. The country, society, school and family should care about this project jointly, sow seeds of traditional culture in the heart of children and help them bloom in the future.

\section{REFERENCES}

[1] Feng Jianjun. Life and Education [M]. Beijing: Educational Science Publishing House, 2004:163 (in Chinese)

[2] Ma Jianjun. Integration of Excellent Traditional Culture and Education for Children [N]. China Education Daily, 2016-05-01(2) (in Chinese)

[3] Schiller. Collected Works of Schiller (Volume 6) [M], translated by Zhang Jiajue, Zhang Yushu, Sun Fengcheng. Beijing: People's Literature Publishing House, 2005:183

[4] Sipe, Lawrence. Using Picture books to Teach Art History [J]. Studies in Art Education, 2001 (3)

[5] [American] Lowenfeld. Creative and Mental Growth [M]. Translated by Wang Deyu. Changsha: Hunan Fine Arts Publishing House, 2002 (2) $: 10$ 